\title{
Preliminary Design of Industrial Symbiosis of Smes Using Material Flow Cost Accounting (MFCA) Method
}

\author{
Rahayu Siwi Dwi Astuti ${ }^{1, *}$, Arieyanti Dwi Astuti ${ }^{1}$, Hadiyanto $^{1,2}$ \\ ${ }^{1}$ Master Program of Environmental Studies, School of Postgraduate Studies Diponegoro University, Semarang - Indonesia \\ ${ }^{2}$ Chemical Engineering Department, Faculty of Engineering Diponegoro University, Semarang - Indonesia
}

\begin{abstract}
Industrial symbiosis is a collaboration of several industries to share their necessities such material, energy, technology as well as waste management. As a part of industrial ecology, in principle, this system attempts to emulate ecosystem where waste of an organism is being used by another organism, therefore there is no waste in the nature. This system becomes an effort to optimize resources (material and energy) as well as minimize waste. Considerable, in a symbiosis incure material and energy flows among industries. Material and energy in an industry are known as cost carriers, thus flow analysis in this system can be conducted in perspective of material, energy and cost, or called as material flow cost accounting (MFCA) that is an economic and ecological appraisal approach. Previous researches shown that MFCA implementation could be used to evaluate an industry's environmental-related efficiency as well as in planning, business control and decision making. Moreover, the MFCA has been extended to assess environmental performance of SMEs Cluster or industrial symbiosis in SMEs Cluster, even to make preliminary design of an industrial symbiosis base on a major industry. This paper describes the use of MFCA to asses performance of SMEs industrial symbiosis and to improve the performance.
\end{abstract}

\section{Introduction}

Nowadays most of industries are facing demands not only to increase production and economic benefits but also responsibility for environmental sustainability and health at the same time. However the production process will always be related to the environment; raw materials extracted from the environment, energy used and emissions released into the environment. This relationship encourages the development of industrial ecological concepts.

The concept of industrial ecology relies on attempt to emulate ecosystem principles, where there is a mutual relationship between living organisms. In the nature, the relationships have a consequence of zero waste system. The waste generated by the organism will be utilized by other such that nothing is wasted. This concept is used in industrial ecology as a base of the concept of resource optimization and waste minimization.

An important part of industrial ecology is industrial symbiosis, where inter-industrial relations are realized by the exchange of resources, knowledge and technology or waste co-management. As the flow of material or energy plays an important role in this symbiosis, the performance of this system can be measured by assessing the efficiency of this material/energy flow. In the industrial world, the efficiency of material/energy flow will be more meaningful when expressed in economic value. One of assessment tools that can be used to measure is Material Flow Cost Accounting (MFCA).

The MFCA assesses the performance of a production process by analyze the material/energy flow from the initial process to final, step by step. It will show the efficiency of material/energy use throughout the production process. This method has been clearly stated in ISO 14051. This method is helpful for entrepreneurs to improve the efficiency of their business while improving their environmental performance. The MFCA is described in section 3.

MFCA concepts have also been implemented in supply chains [1][2] as explained in ISO 14052 (2017). This method assesses the economic and environmental performances of a supply chain by calculating materials/energy flows among involved industries. Ecological and economic value of materials/energy of each industry, output and material loss can be calculated and used to design optimization and efficiency of raw materials/energy. MFCA implementation in a supply chain is illustrated in section 4.

\footnotetext{
${ }^{*}$ Corresponding author: siwidwiastuti@gmail.com
} 
The concept of MFCA implemented to supply chain is mostly applied to industrial symbiosis, that can be regarded as expansion of supply chain. In a supply chain system involved upstream and downstream industries of a product system - i.e system of canned fish products. The supply chains of the canned fish industry may consist of fishing industry, fish freezing, canning fish, tomato sauce industry, and tincan industry. In industrial symbiosis, the system involved not only industries supplies raw materials for the main products, but also involve industries that utilize byproducts even provide/share waste management, resulting in various products. For example in fish canning industry, industries that can be involved are fishing industry, fish freezing, canning fish, tomato sauce industry and canned industry, fish meal industry, fish protein concentrate industry, fish collagen industry, fish paste, silage, waste treatment, water treatment and fertilizer. In this system, the main raw material is not only fish, but also by-product such as stomach, bone, head, even waste water. An overview of the implementation of MFCA in industrial symbiosis is illustrated in section 5 .

Assessment of material/energy flow in an area also can be used to determine whether, in a region, industrial symbiosis can also be developed[3]. In the area, input-output materials/energies are identified, then materials that have not been optimally utilized are identified and appropriate technologies are selected. The congruence of available material/energy flow and selected technology are base of the initial design of industrial symbiosis development. This initial design is illustrated in section 6. Scientists believe the development of appropriate industrial symbiosis will help to improve the economic and environmental performance of an industrial estate..

\section{Industrial Symbioses}

Industrial symbiosis is part of the industrial ecology where several industries establish mutually beneficial cooperation relationships that enhance competitive advantage by involving material, energy, water and/or by-product exchange[4]. Examples of excellent and inspiring applications are those built in Kalunborg, Denmark. The definition of industrial symbiosis has been so far developed. According to Chertow [4] the key to industrial symbiosis is the possibility of collaboration and synergism in the presence of geographical proximity. Maltin [5] defines industrial symbiosis as a long-term symbiotic relationship between firms involving physical exchange and human or technical exchange as an effort to improve environmental performance and enhance collective competitive advantage, so that this collaboration includes the transformation of economic outlook, environmental and social performance. The exchange involved material, energy, water, by-product, even infrastructure, experience and knowledge[5]. In line with Maltin[5], Lombardi \& Laybourn [6], explained the synergistic relationship in industrial symbiosis can include creating and sharing knowledge about new input resources, value-added output products and improved processes and techniques. But they did not consider the role of geographical proximity to be an important factor[6]. The repeated implementation of industrial symbiosis produces beneficial industrial ecosystems reducing the use of raw materials and pollution, improves systemic energy efficiency, reduces waste volumes, increases the number and type of outputs of economic value [7].

The design of industrial symbiosis should pay attentions: 1). The corresponding input output of the industries involved; 2). The technological process efficiency used by each industry that determines the volume of waste emissions and the number of primary inputs [8]. Murat et al. [8] describes three conditions of industrial symbiosis: 1). Perfect symbiosis; 2). Excess waste; 3) lack of waste. To approach the condition of the perfect symbiosis and overcome the second and third conditions, Murat et al. [8] suggested two stages of symbiotic design as: 1). Physical and technological conditions must be determined; 2). Related to economic comfort, contract, and willingness to persist in the implementation of industrial symbiosis.

\section{Material Flow Cost Accounting (MFCA)}

MFCA is one of the tools of Environmental Management Accounting (EMA) that develops material flow models, traces and quantifies the flow and supply of materials within an organization in physical and monetary units [9]. In this method, the costs in the production system are distributed on lost products and materials to enable companies to identify the added value they do not get as a result of the missing material [10]. Furthermore, Tachikawa [9], added that by identifying each material and its cost (including material costs, waste treatment and handling), we can look at each source of waste and identify its reduction opportunities. 


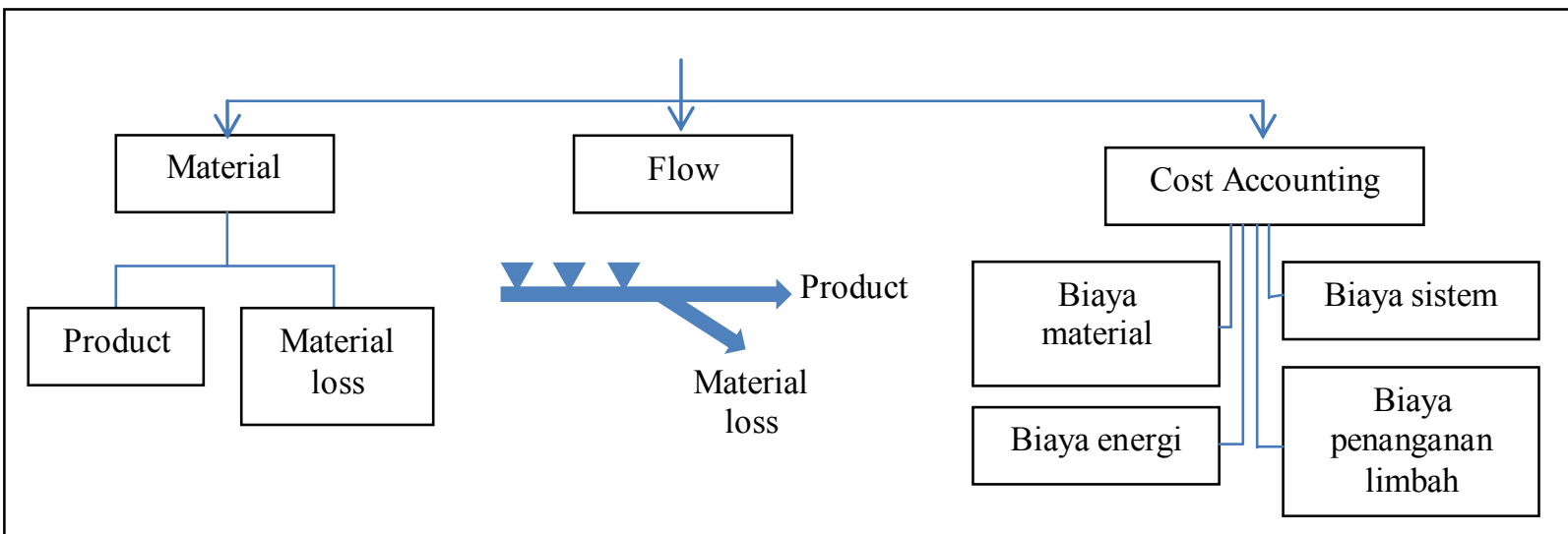

Fig. 1. MFCA Main Element

Source: adapted from Tachikawa [9]

ISO 14051 (2011) explain MFCA guidance. It describes the fundamentals and principles of MFCA. The principles of MFCA include understanding material flow and energy use, linking physical and monetary data, ensuring the accuracy, completeness and compatibility of physical data, and estimating and linking costs with material losses. MFCA Principles consist of:

1. Quantity center

The quantity center is selected part or part of the process that measured in physical and monetary units. Quantity centers are basis for data collection. The data collected includes: 1). Material flow and energy use; 2) material costs, energy costs, system costs and waste management costs.

2. Material balance

The material entering and exiting a quantity center must be balanced. Comparisons between inputs and outputs and inventory changes are made to identify significant missing materials or other data gaps.

\begin{tabular}{|c|c|c|c|c|}
\hline \multicolumn{3}{|l|}{ Input } & \multicolumn{2}{|r|}{ Output } \\
\hline \multirow[t]{2}{*}{ Material $95 \mathrm{~kg} \longrightarrow$} & \multicolumn{2}{|c|}{ Quantity Center } & $\rightarrow$ & Product $70 \mathrm{~kg}$ \\
\hline & $\begin{array}{c}\text { Initial } \\
\text { Inventory of } \\
\text { material } \\
15 \mathrm{~kg}\end{array}$ & $\begin{array}{c}\text { Final } \\
\text { Inventory of } \\
\text { material } \\
10 \mathrm{~kg}\end{array}$ & $\rightarrow$ & Material loss $30 \mathrm{~kg}$ \\
\hline
\end{tabular}

Fig 2. Material Balance in a Quantity Centre

Source: ISO, 2011

3. Cost calculation

Calculation is done on three cost, namely:

material cost, energy cost and system cost.

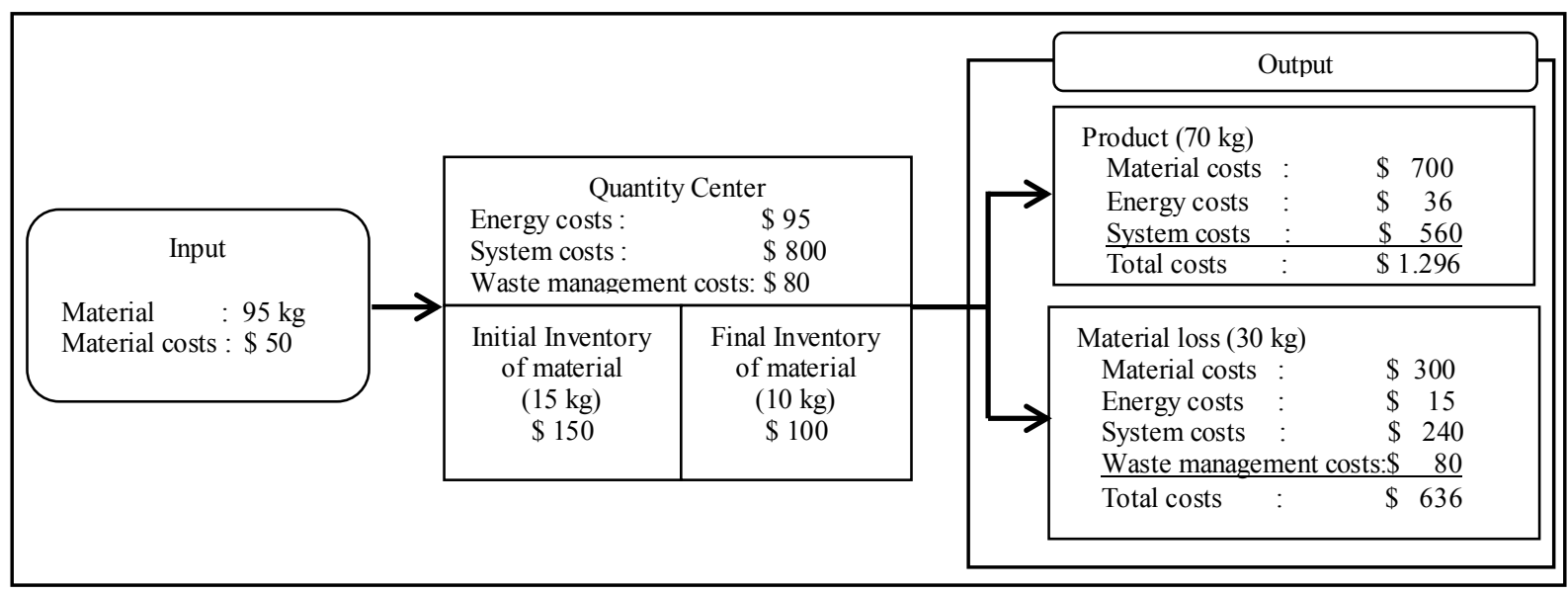

Fig 3. Costs calculation in a quantity centre

Source: ISO, 2011 
4. Material flow model

Production, recycling, and other systems are illustrated by the visual models of some quantity centers in which the material is distributed, used or modified and the movement of materials among the quantity centers.

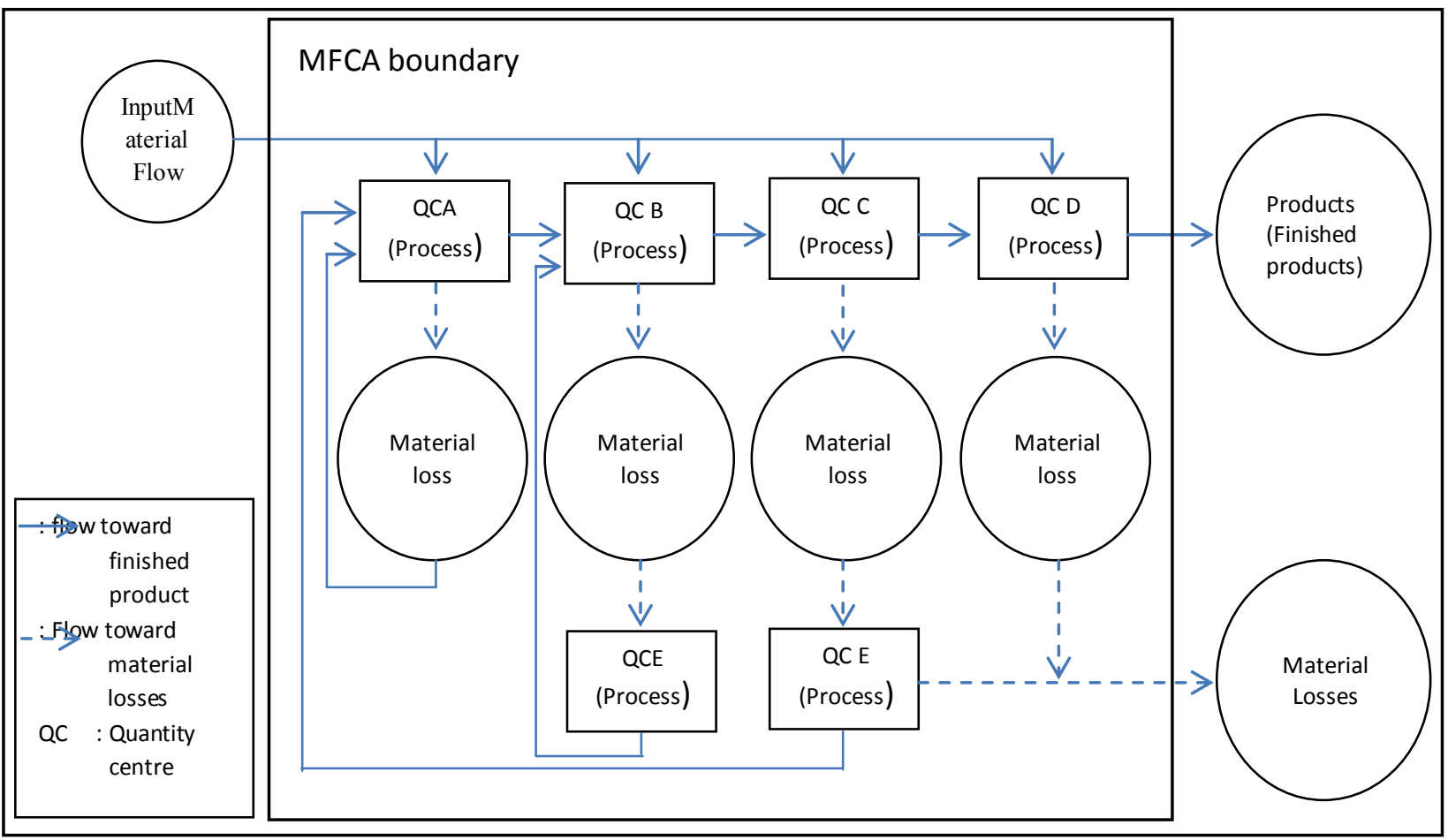

Fig 4. Material Flow for a process within the MFCA boundary

Source: ISO, 2011

\section{Extension of MFCA to a supply chain}

Prox [1] illustrated well MFCA implementation in supply chain. It is mentioned that the internal or environmental losses identified by the MFCA are influenced by the supply of suppliers or the final product characteristics requested by the customer. The solution to this problem is the collaboration between suppliers and customers as well as an understanding of the overall production system. Prox [1] illustrated every company's inefficiencies are potentially improved. According to him, inefficiencies in small percentages experienced by each stage of the process, eg 1-2\% can be accepted, but when accumulated from the whole system can reach $20-60 \%$.

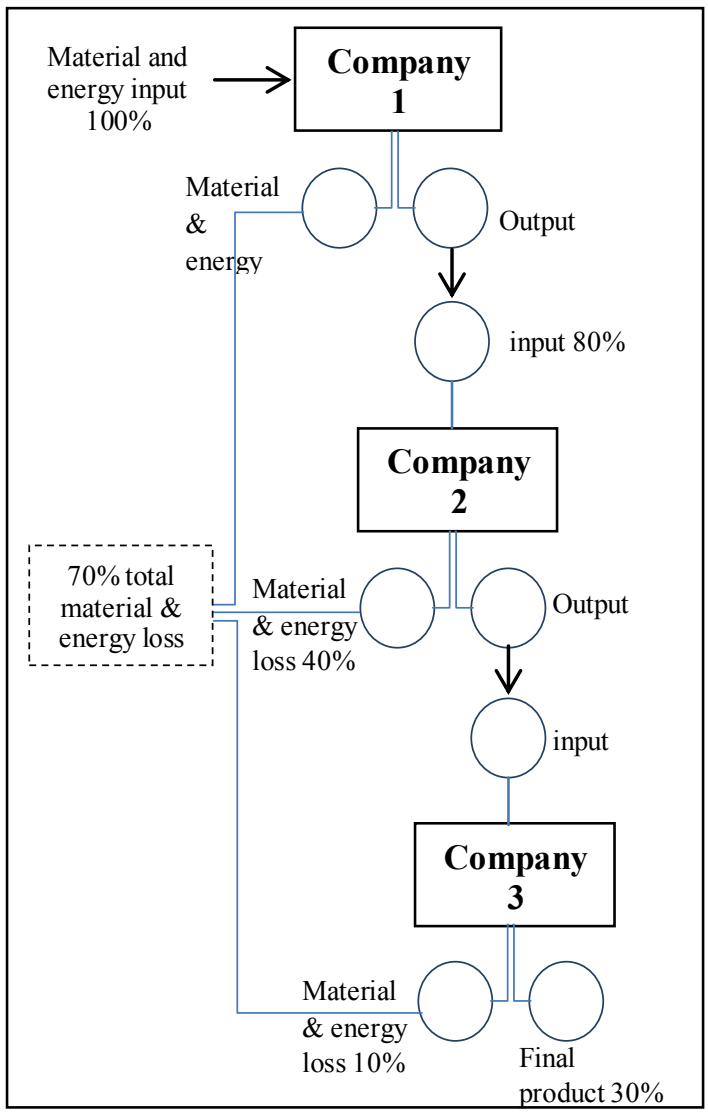

Fig 5.Material loss in supply chain Source: adapted from Prox [1] 


\section{Implementation of MFCA to SMEs Industrial Symbiosis}

An industrial symbiosis can be illustrated such as supply chain system. But industrial symbiosis involved some different flows of material/energy among different industries. In other word, a industrial symbiosis might has several supply chains. Material flows throughout the system can be either by-product or waste. As effort of optimization of resource utilization (materials/energy) and waste minimization, the researchers found that industrial symbiosis can provide significant advantages both in terms of environment and economy.

A simple example of industrial symbiosis can be described as follows.

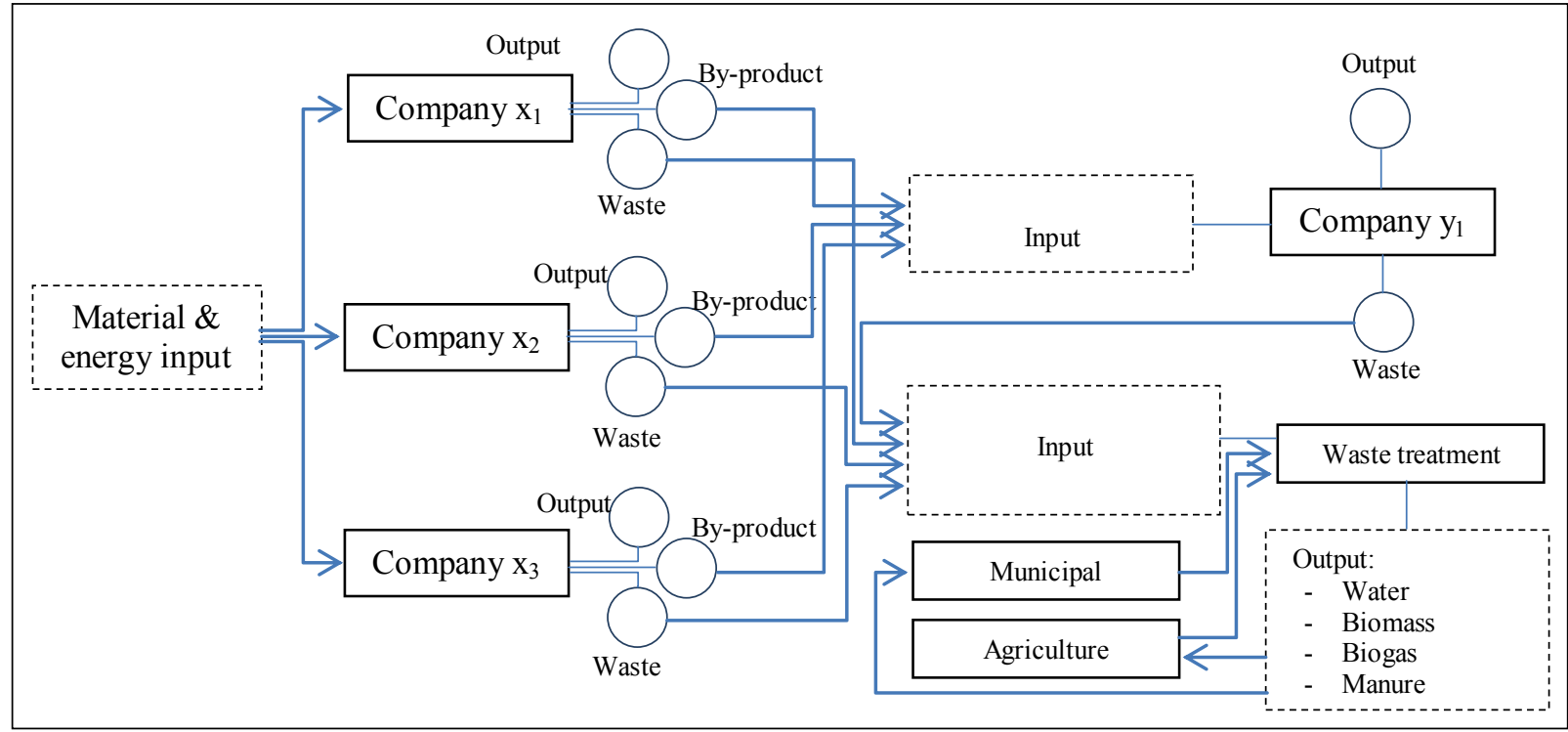

Fig 6. Material flow in an industrial symbiosis

Cimren, et al. [11] used MFCA to optimize the by-product synergy (BPS) network in Kansas City, Missouri. The study found that cooperation to improve the profitability of Kansas City's network system could save \$ 15 million annually with a total cost reduction of $29 \%$, reduction $28.5 \%$ of the company's average cost, reduction in $30 \%$ carbon dioxide emissions $(\mathrm{CO} 2)$, and reduction of $37 \%$ waste to final landfill[11]. The MFCA application was used by $\mathrm{Gu}$, et al. [12] to model the mathematical optimization control of his research in Le Havre France. This control model aimed to help industries reduce environmental costs and reduce environmental impacts simultaneously[12][13].

\section{Preliminary Design of Industrial Symbiosis Using MFCA}

Ulhasanah \& Goto [14] provided an example of how MFCA is used to see the possibilities of industrial symbiosis can be built and provide benefits to the cement industry in Indonesia. The MFCA provides an overview of how the input- output efficiency of a group of industries and how the utilization has been done. Furthermore, taking into account the technology to be applied we can estimate the inputs and outputs of the industry to be developed, and also estimate opportunity of implementation[8].

For example, Ulhasanah and Goto[14] proposed two industrial symbiotic scenarios (scenarios 2 and 3 ) that were compared to existing conditions (scenario 1). Scenario 2 involved recycling cement kiln dust (CKD) and utilized municipal waste and surrounding industries as alternative energy sources. Scenario 3 involved scenarios 1 and 2 coupled with the utilization of waste from other cities around it as an alternative energy sources. MFCA was used to calculate the total product cost, system cost and material loss cost of the three scenarios and compared it, and concluded that scenarios 2 and 3 can save raw materials by 37 billion IDR/year, surplus energy costs in scenario 2 of 52.028 billion IDR/year, while in scenario 3 the surplus energy cost is 61.390 billion IDR/year[14]. 


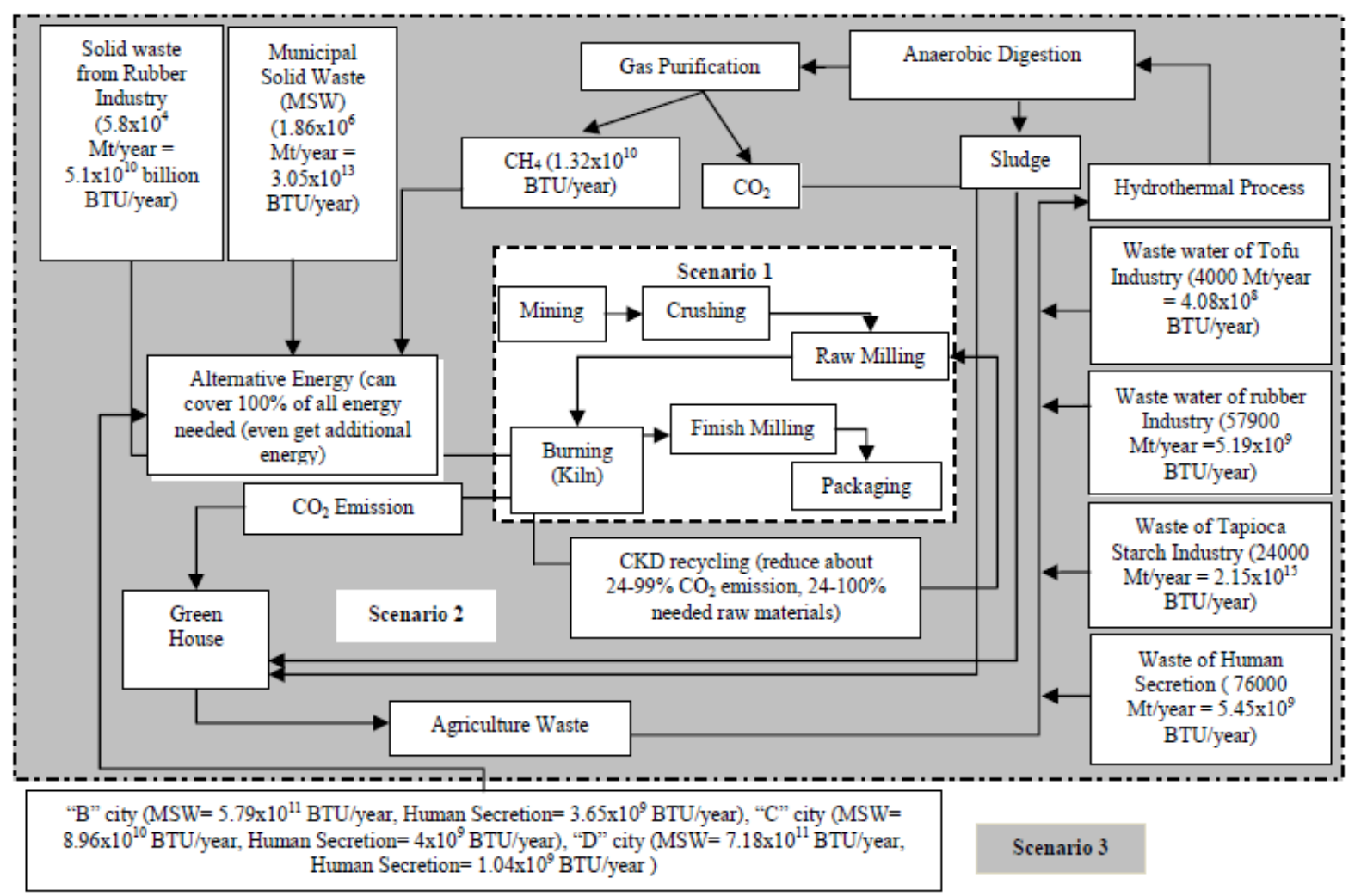

Fig. 7. Scenarios of design of alternative material exchange Source: Ulhasanah \& Goto[14].

We often find small and medium industries built in urban areas, spread among settlements and other buildings. Its presence in society is often followed by a simple symbiotic relationship between the industry and the urban community. For example small food processing industries such as tofu, tempeh or fish processor. These industries produce waste and/or by-products that can be utilized by the community, such as tofu dregs or fish guts that can be used as animal feed, even some types of byproducts still have nutritional value and taste that can be sold as food, for example tofu dregs, fish head, and others. Although this relationship seems to be beneficial and can reduce the waste, its benefits, effectiveness and efficiency need to be tested. Alternatively, many technological options can be used to construct several energy symbiotic scenarios, depending on the suitability of the inputoutput of the production processes. By calculating the total cost of product, system and material loss and comparing it, we may propose conclusion and recommendation scenarios as the initial design of industrial symbiosis as did Ulhasanah and Goto [14].

\section{Conclusions}

The conclusions that can be drawn from the above description are:

1. MFCA can be used to assess the environmental and economic performance of an industry, supply chain and industrial symbiosis,

2. By calculating the total cost of product, system and material loss of an industrial or industrial estate and inventory of waste/byproduct utilization technology, it can be designed the initial scenario of industrial symbiosis.

\section{Reference:}

1. M. Prox, Procedia CIRP 29, vol. 29, pp. 486491, (2015).

2. M. Nakajima, A. Kimura, and B. Wagner, $J$. Clean. Prod., vol. 108, pp. 1302-1309, (2015).

3. M. R. Chertow, "“ Uncovering ' Industrial Symbiosis," vol. 11, no. 1, (2007).

4. M. R. Chertow, "Industrial Symbiosis : Literature and Taxonomy," (2000).

5. M. Maltin, IIIEE Reports, no. October,(2004).

6. D. R. Lombardi and P. Laybourn, vol. 16, no. 1, (2012).

7. N. Gertler, Industrial Ecosystems: Developing Sustainable Industrial Structures. Thesis. Massachussets: Massachussets Institute of Technology, (1995).

8. D. Murat, V. Alessio, and V. Albino, J. Clean. Prod., vol. 129, pp. 537-547, (2016).

9. H. Tachikawa, Manual on Material Flow Cost Accounting ISO 14051. Tokyo: Asian Productivity Organization,(2014).

10. M. Schmidt, J. Clean. Prod., pp. 1-10, (2014).

11. E. Cimren, J. Fiksel, M. E. Posner, and K. 
Sikdar, vol. 15, no. 2, (2011).

12. C. Gu, S. Leveneur, L. Estel, and A. Yassine, "Industrial Symbiosis Optimization Control Model for the exchanges of the material / energy flows in an industrial production park," pp. 1015-1020, (2013).

13. C. Gu, S. Leveneur, L. Estel, and A. Yassine,
Energy Procedia, vol. 36, pp. 243-252, (2013).

14. N. Ulhasanah and N. Goto, Int. J. Environ. Sci. Dev., vol. 3, no. 6, (2012).

15. ISO 14051 : 2011(E). Environmental Management - Material Flow Cost Accounting - General Framework 